\title{
Is Lumbosacral Transitional Vertebra Associated with Degenerative Lumbar Spinal Stenosis?
}

\author{
Janan Abbas $\left(\mathbb{D},{ }^{1,2}\right.$ Natan Peled, ${ }^{3}$ Israel Hershkovitz, ${ }^{1}$ and Kamal Hamoud ${ }^{2,4,5}$ \\ ${ }^{1}$ Department of Anatomy and Anthropology, Sackler Faculty of Medicine, Tel Aviv University, Tel Aviv 6997801, Israel \\ ${ }^{2}$ Department of Physical Therapy, Zefat Academic College, Zefat 13206, Israel \\ ${ }^{3}$ Department of Radiology, Carmel Medical Center, Haifa 3436212, Israel \\ ${ }^{4}$ Faculty of Medicine in the Galilee, Bar-Ilan University, Zefat 1311502, Israel \\ ${ }^{5}$ Department of Orthopaedic Surgery, The Baruch Padeh Poriya Medical Center, Tiberias 1520800, Israel
}

Correspondence should be addressed to Janan Abbas; janan1705@gmail.com

Received 8 December 2018; Revised 18 April 2019; Accepted 26 May 2019; Published 10 June 2019

Academic Editor: William B. Rodgers

Copyright (C) 2019 Janan Abbas et al. This is an open access article distributed under the Creative Commons Attribution License, which permits unrestricted use, distribution, and reproduction in any medium, provided the original work is properly cited.

\begin{abstract}
The aim of this study was to shed light on the association between lumbosacral transitional vertebra (LSTV) and degenerative lumbar spinal stenosis (DLSS). A cross-sectional retrospective study was performed on 165 individuals that were diagnosed with clinical picture of DLSS (age range: 40-88 years; sex ratio: $80 \mathrm{M} / 85 \mathrm{~F}$ ) and 180 individuals without DLSS related symptoms (age range: 40-99 years; sex ratio: 90M/90F). All participants had undergone high-resolution CT scan for the lumbar region in the same position. We also used the volume rendering method to obtain three-dimensional CT images of the lumbosacral area. Both males and females in the stenosis group manifest greater prevalence of LSTV than their counterparts in the control group $(\mathrm{P}<0.001)$. Furthermore, the presence of LSTV increases the likelihood of degenerative spinal stenosis (odds ratio $=3.741, \mathrm{P}<0.001$ ). In the control group, LSTV was more common in males, and sacral slope angle of males was significantly greater in LSTV group compared to non-LSTV. This study indicates that LSTV was significantly associated with symptomatic DLSS.
\end{abstract}

\section{Introduction}

Lumbar spinal stenosis is one of the most commonly diagnosed and treated conditions among the elderly population $[1,2]$. Its clinical prevalence is about $47 \%$ in adults with lower extremities symptoms and $13 \%$ in those who seek help from a specialist for low back pain (LBP) [3-5]. Degenerative lumbar spinal stenosis (DLSS) is considered the most common acquired type [6] and is associated with degenerative changes of the three-joint complex, ligamentum flavum thickening, and osteophytes formation [7-9].

Lumbosacral transitional vertebrae (LSTV) are common congenital spinal anomalies, referring to a total or partial unilateral or bilateral fusion of the transverse process of the lowest lumbar vertebra to the sacrum [10]. Generally, the term LSTV is used to avoid having to decide whether the vertebra is sacralized L5 or a lumbarized S1 because it is not possible to view the entire spine [10]. Their reported prevalence range between $4 \%$ and $36 \%$ [11-14] with a remarkable preference in men $[15,16]$. It has been reported that LSTV are generally easier to detect on CT images than on magnetic resonance imaging (MRI) [17, 18].

Although several studies have correlated the presence of LSTV with LBP and nerve-root symptoms [10, 19-21], other investigators have disputed this [13, 22-25]. In addition, some studies have noted that LSTV might increase the risk for developing lumbar spine degeneration at the level above the transitional vertebra $[23,26]$ in LBP individuals; however, data regarding LSTV and DLSS are ambiguous. Additionally, the association between LSTV and lumbar curvatures is uncommon $[27,28]$.

The aims of this study were (1) to identify the prevalence of LSTV in symptomatic DLSS, (2) to reveal whether the presence of LSTV affects disc height at the level above the LSTV, and (3) to examine the association between LSTV and lumbar lordotic curvatures. 


\section{Materials and Methods}

2.1. Study Design. This is a cross-sectional retrospective study with two groups of individuals [29]. The first group (control) included 180 individuals without spinal stenosis related symptoms (age range: 40-99 years; sex ratio: 90M/90F). This group was randomly collected (2008 to 2010) from a pool of subjects referred to the Department of Radiology, Carmel Medical Center, Haifa, Israel, for abdominal CT scans due to abdominal problems. The second group included 165 patients with symptomatic DLSS (age range: $40-88$ years; sex ratio: $80 \mathrm{M} / 85 \mathrm{~F}$ ), who were enrolled from 2006 to 2010 and had intermittent claudication accompanied by other symptoms related to spinal stenosis (LBP and radicular pain) [30, 31]. The CT scans of these patients showed a reduced crosssectional area (CSA) of the dural sac $\left(<100 \mathrm{~mm}^{2}\right)$ [32-34] of at least one lumbar level. The diagnostic criteria for DLSS were based on the combination of symptoms and signs together with the imaging findings [35]. Individuals under 40 years of age as well as those with congenital stenosis (AP diameter of the bony canal < $12 \mathrm{~mm}$ ) [36, 37], fractures, spondylolysis, tumors, Paget's disease, steroid treatment, severe lumbar scoliosis (>20 degrees), and iatrogenic conditions (after laminectomy, after fusion) were excluded from the study.

A high-resolution CT image (Brilliance 64, Philips Medical Systems, Cleveland, $\mathrm{OH}$; slice thickness $0.9-3 \mathrm{~mm}$, voltage $120 \mathrm{kV}$, current 150-570 mA) was utilized which enabled scan processing in all planes and allowed a $3 \mathrm{D}$ reconstruction of the lower lumbar region. All CT images for both groups were taken in the supine position with extended knees.

This study was approved by the ethical committee of the Carmel Medical Center (0083-07-CMC).

2.2. Identification of LSTV. The presence of LSTV was based on Castellvi classification system [10] using the volume rendering method to obtain three-dimensional CT images of the lumbosacral area (Figure 1). The definition of LSTV was performed by the first author (JA) under the supervision of a diagnostic radiologist. The participants with positive LSTV were then recorded into unilateral or bilateral anomalies regardless of the severity of LSTV.

In this study, the disc level above the LSTV was related to the segment between the last lumbar vertebra and the sacrum, irrespective of whether the LSTV was a sacralized L5 or a lumbarized S1 (following the study of Otani et al.) [23].

2.3. Sacral Slope Angle (SSA)/Lumbosacral Angle. SSA was measured in the mid-sagittal plane, using a modification of Ferguson's method [38] (adapted to CT images when the individual is in a supine position) and defined as the angle formed by the line of the upper end plate of the sacrum and the horizon.

2.4. Lumbar Lordosis Angle (LLA). LLA was evaluated in the sagittal plane between the lines of upper endplate of L1 and S1 following Cobb's method [39] (adapted to the sagittal plane).

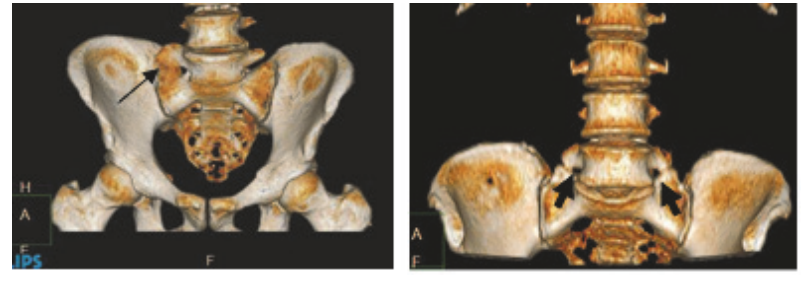

FIgURE 1: Lumbosacral transitional vertebra as evident in 3dimensional images: unilateral (left) and bilateral (right) anomalies.

2.5. Intervertebral Disc Height (IDH). IDH was measured in the mid-sagittal plane at three points: anterior, middle, and posterior. Mean IDH was then calculated for the three different locations.

2.6. Statistical Analysis. The sample size of this study was based on the power analysis $(\alpha=0.05, \beta=0.8)$ and all the statistical analyses were done via SPSS version 20. ChiSquare test was performed to compare the prevalence of LSTV between the study groups (control and stenosis) for each gender separately. A logistic regression analysis was also used to determine the association between DLSS and LSTV (dependent variable: DLSS; independent variables: LSTV, age, gender, BMI) using "Forward LR" method. To identify the relationships between LSTV with lumbar curvatures and/or disc height we used t-test for each gender separately for the control group (adjusted for age and BMI).

Kappa and intraclass correlation (ICC) coefficients were calculated to determine the intratester and intertester reliability of LSTV and the metric parameters, respectively (repeated measurements of 20 individuals). Intratester reliability was assessed by one of the authors (JA) who identified the LSTV presence twice within intervals of 3-5 days. Intertester reliability involved two testers (JA and $\mathrm{KH}$ ), who took the measurements within an hour of each other. Both testers were blinded to the results of the measurements. Significant difference was set at $\mathrm{P}<0.05$.

\section{Results}

Kappa coefficient tests for both intra- and intertester reliability were very high, 0.990 and 0.980 , respectively. In addition, the intraclass correlation coefficient (ICC) test for intratester and intertester reliability of the parametric variables (e.g., disc heights and lumbar curvatures) ranged from ICC $=0.960$ to 0.984 and from ICC $=0.943$ to 0.980 , respectively.

Data for age and body mass index (BMI) of both study groups (control vs. stenosis) is presented in Table 1.

3.1. Prevalence of LSTV in the Study Groups. We found that 95 individuals who manifest spinal stenosis (57.6\%) have LSTV (unilateral and bilateral together) compared to 47 (26.1\%) in the control group $(\mathrm{P}<0.001)$.

The prevalence of LSTV for each anomaly (unilateral and bilateral separately) in both stenosis males and females was significantly higher compared to their counterparts in the 
TABLE 1: Age and body mass index values of the study groups (control vs. stenosis) for each gender separately.

\begin{tabular}{|c|c|c|c|c|c|c|}
\hline \multirow[t]{2}{*}{ Variables } & \multicolumn{2}{|c|}{ Males } & \multicolumn{4}{|c|}{ Females } \\
\hline & $\begin{array}{c}\text { Control } \\
(\text { mean } \pm S D)\end{array}$ & $\begin{array}{l}\text { Stenosis } \\
(\text { mean } \pm \text { SD })\end{array}$ & $\mathrm{P}$ value & $\begin{array}{c}\text { Control } \\
(\mathrm{mean} \pm \mathrm{SD})\end{array}$ & $\begin{array}{l}\text { Stenosis } \\
(\text { mean } \pm S D)\end{array}$ & $\mathrm{P}$ value \\
\hline Age (years) & $62.9 \pm 12.38$ & $66.2 \pm 10.82$ & 0.066 & $62 \pm 12.97$ & $62.5 \pm 8.63$ & 0.795 \\
\hline BMI $\left(\mathrm{kg} / \mathrm{m}^{2}\right)$ & $27.4 \pm 4.21$ & $28.9 \pm 4.55$ & 0.021 & $27.61 \pm 5.13$ & $31.48 \pm 5.83$ & $<0.001$ \\
\hline
\end{tabular}

SD: standard deviation.

TABLE 2: A logistic regression analysis demonstrating the variables that significantly associate with degenerative lumbar stenosis.

\begin{tabular}{lccc}
\hline Variable & OR & (CI) $95 \%$ & P value \\
\hline BMI & 1.112 & $1.061-1.116$ & $<0.001$ \\
LSTV & 3.741 & $2.342-5.974$ & $<0.001$ \\
\hline LST
\end{tabular}

LSTV: lumbosacral transitional vertebra, OR: odds ratios, CI: confidence intervals, BMI: body mass index.

TABLE 3: Mean age, sacral slope (SS), lumbar lordosis (LL), and intervertebral disc height (IDH) in the LSTV and non-LSTV for the control group.

\begin{tabular}{lccc}
\hline & $\begin{array}{c}\text { Non-LSTV } \\
\text { Mean } \pm \text { SD }\end{array}$ & $\begin{array}{c}\text { LSTV } \\
\text { Mean } \pm \text { SD }\end{array}$ & P value \\
\hline Males & $(\mathrm{n}=59)$ & $(\mathrm{n}=31)$ & \\
Age & $61.5 \pm 12$ & $65.6 \pm 11$ & 0.128 \\
BMI & $27.3 \pm 4.5$ & $27.6 \pm 3.5$ & 0.704 \\
SS & $40.8 \pm 6$ & $44.4 \pm 7$ & 0.048 \\
LL & $48.2 \pm 8$ & $52.4 \pm 11$ & 0.089 \\
IDH & $9.7 \pm 2$ & $7.8 \pm 2$ & $<0.001$ \\
\hline Female & $(\mathrm{n}=62)$ & $(\mathrm{n}=16)$ & \\
Age & $63.6 \pm 11$ & $69.6 \pm 11$ & 0.071 \\
BMI & $27.6 \pm 5$ & $27.5 \pm 5.6$ & 0.915 \\
SS & $41.1 \pm 7$ & $45.6 \pm 8$ & 0.076 \\
LL & $51.4 \pm 12$ & $55.1 \pm 11$ & 0.253 \\
IDH & $8.6 \pm 2$ & $8.4 \pm 2$ & 0.765 \\
\hline
\end{tabular}

SD: standard deviation, n: sample size, LSTV: lumbosacral transitional vertebra.

control group $(\mathrm{P}<0.001)$ (Figures 2 and 3$)$. In the stenosis group, there were no significant differences in the degree of stenosis (according to cross-sectional areas of dural sac from L1-2 to L5-S1) between the unilateral and bilateral LSTV.

Furthermore, the presence of LSTV (unilateral and bilateral combined) was found to increase the likelihood of DLSS development (odds ratio $=3.741$, confidence intervals $=2.342$ 5.974, $\mathrm{P}<0.001$ ) (Table 2). However, logistic regression analysis for bilateral and unilateral LSTV separately showed different $\mathrm{OR}$ (odds ratio): $\mathrm{OR}=5.451, \mathrm{CI}$ (confidence intervals) $=$ 2.820-10.535, $\mathrm{P}<0.001 ; \mathrm{OR}=2.889, \mathrm{CI}=1.666-5.008, \mathrm{P}<0.001$, respectively.

3.2. Association between LSTV and Gender, Lumbar Curvatures, and Disc Height. Among those who manifest LSTV in

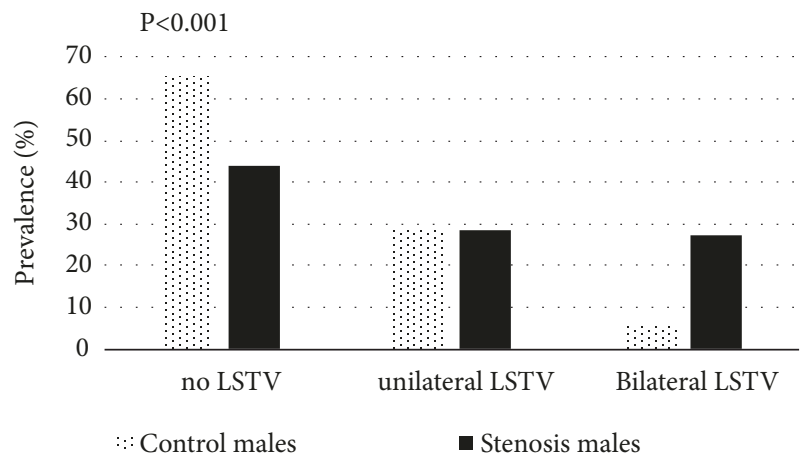

Figure 2: Prevalence (\%) of lumbosacral transitional vertebra (LSTV) in the male groups (control vs. stenosis).

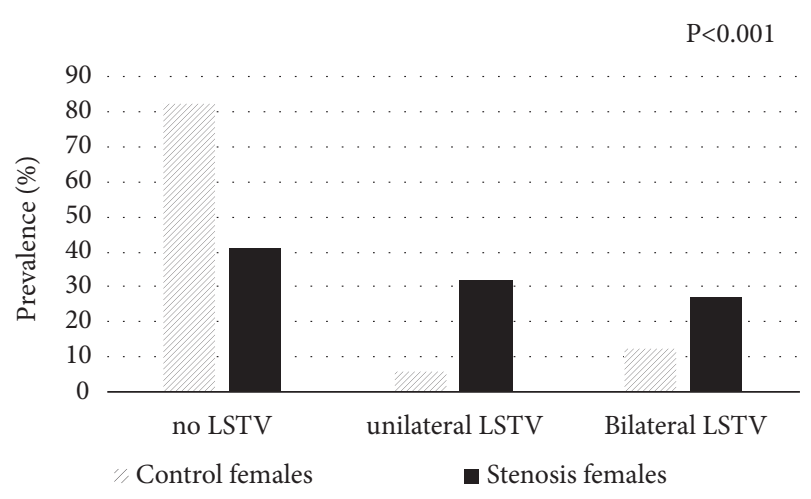

FIgURE 3: Prevalence (\%) of lumbosacral transitional vertebra (LSTV) type in the female groups (control vs. stenosis).

the control group $(\mathrm{n}=47)$ we found 31 males and 16 females ( $66 \%$ vs. $34 \%, \mathrm{P}=0.017$ ).

As considerable differences in mean age between the LSTV and non-LSTV individuals in the control females group have been reported ( $69.6 \pm 11.3$ vs. $60.4 \pm 12.7 ; \mathrm{P}=0.009$, respectively), we reduced the sample size of the females nonLSTV (from 74 to 62) to avoid age bias (Table 3).

In males, the mean disc height of the supradjacent level to LSTV was significantly smaller compared to the same levels in individuals without LSTV. Additionally, lumbar curvatures were greater in individuals with LSTV compared to nonLSTV group, yet significant difference was noted only for sacral slope (Table 3). In females, however, neither disc height nor spine curvatures were associated with LSTV. 


\section{Discussion}

As this study, to our knowledge, is the first to establish the prevalence of LSTV in symptomatic DLSS, it could not be debated with others.

Symptomatic lumbar spinal stenosis requires appropriate specific history and physical examination findings combined with radiographic findings [30]. Neurogenic claudication and radicular pain constitute the best described clinical picture while neurogenic claudication is the most common one. This symptom is a variable pain or discomfort with walking or prolonged standing that radiates beyond the spinal area into one or both buttocks, thighs, lower legs, or feet [35]. It also exhibits typical provocative features, such as improvement with sitting or lumbar flexion, and worsening with lumbar extension [30, 35]. In contrast, radicular pain may often not exhibit the provocative features seen in neurogenic claudication. Furthermore, low back pain is often present and its actual part in this syndrome is controversial [35].

Our result indicates that the prevalence of LSTV in the DLSS group (57\%) is about 2 times greater than the control group (26\%) and is much higher than the previous reported studies (range: 4-36\%) that based their investigation on LBP individuals as well as healthy and general population [14-16, $22,24,40-42]$. We believe that the wide range of this reported incidence could likely be due to differences in individual diagnostic and classification criteria, observer error, imaging techniques, and other confounding factors of the studied population [43]. It is noteworthy that the prevalence of LSTV for the control group (26\%) falls within the range reported by other studies (16-30\%) that were conducted on general population $[14,16,22]$.

This study revealed that stenosis males and females manifest greater prevalence of LSTV compared to the control. Additionally, the presence of LSTV increases 3.741 times the risk of developing DLSS. Although Elster (1989) stated that spinal stenosis and nerve-root canal stenosis were much more common at the level immediately above a transitional vertebra than at any other level [21], the correlation between spinal stenosis and LSTV was refuted [21, 44].

It is well-known that one of the main roles of the lumbosacral region is distributing the load from the entire lumbar spine to the hip joints and then to the lower limbs [45]. The transmitted load that passes through the lumbosacral joints includes the three-joint complex such as the intervertebral disc, anteriorly, and 2- facet joints, posteriorly. Mahato (2012) reported that LSTV has the potential to alter the biomechanics of lumbar spine as many of these transitions manifest deformities of the zygapophyseal surfaces and hence cause listhesis at L5-S1 [46]. Furthermore, unilateral LSTV results in asymmetrical biomechanical alterations that can cause facet pain [47] and influence disc degeneration [27]. In anatomical cadavers study, Aihara et al. (2002) found that iliolumbar ligaments above the transitional vertebrae were thinner and weaker than those without LSTV [48]. They suggested that this result was a response to vertebral instability that could subsequently lead to segmental degeneration. It has been also proposed that in the presence of sacralization of L5, when its transvers process is fused or anomalously articulated with the sacrum, motion of L5-S1 segment is restricted [49], which could lead to excessive movements of the upper segment, similar to the adjacent segment pathology after a spinal fusion [50]. Mahato (2013) found that the overall number of trabeculae was reduced in sacralized L5 vertebra, which may emphasize the altered trajectory stress on the lumbosacral junction [51].

We believe that the association between LSTV and DLSS is related to the fact that LSTV increases the mobility and alters the mechanical stress above the transient vertebra that may lead over time to degenerative changes of the three-joint complex [52] causing stenosis. Furthermore, hypermobility and abnormal torque movements at the level above the transitional vertebra have been reported $[22,53]$.

We also found that disc height loss (male groups) above the transition level was significantly associated with LSTV. We assume that the insignificant result obtained for females is due to low number of subjects with LSTV anomaly $(n=16)$. Disc protrusion and/or extrusion occurs more often at the level supradjacent to the LSTV than the same level in patients without $\operatorname{LSTV}[10,21,26]$. This is also true for disc degeneration $[26,54]$. Otani et al. reported that $83 \%$ of patients with disc herniation in the presence of LSTV experience symptoms arising from the last caudal mobile segment, whereas $59 \%$ of patients with disc herniation without transitional vertebra had arising symptoms from the 2nd last mobile segment [23]. Furthermore, a recent study [49] has found that among adolescent patients with sacralization, the L4-5 disc herniation was significantly more common than L5-S1 ( $81.3 \%$ vs. $18.7 \%, \mathrm{P}=0.019)$.

Our results showed that LSTV in the control group has great preference in males than females (66\% vs. $34 \%$, $\mathrm{P}=0.017$ ), which is in agreement with previous reports $[10$, $15,16,55]$. In contrast, other studies stated no statistical correlation between LSTV and gender [56, 57]. Genetic factors are considered to be responsible for the segmentation development of lumbosacral spine [11]. Uçar and colleagues suggested in their wide and well-represented population study $(n=3607)$ that the great LSTV prevalence among males could be a part of body size gender dimorphism in human beings [16]. We assume that the relation between gender and LSTV could partially explain why male lumbar discs (besides other factors, e.g., occupation) were significantly more degenerated than female discs across most ages [58].

We found that sacral slope has a tendency to be greater among LSTV individuals compared to non-LSTV; however, significant difference was noted only for males (44.4 7 vs. $40.8 \pm 6, \mathrm{P}=0.048)$. Although the influence of LSTV on sacral anatomy and lumbar curvature has been less studied in the past, our result is in accordance with some previous studies. Chalian et al. found that both sacral slope and lumbar lordosis were significantly increased in LSTV compared to controls and this finding supports their previous experiences [27]. One study has also reported that L5-S1 accessory articulations were characterized with increased lordotic curves [59]. In contrast, a recent study that was conducted in individuals with LBP reported that sacral tilt was significantly smaller in LSTV than those without LSTV [28]. We believe that the differences between the studied populations of the current 
study and the latter one (general population vs. LBP) may explain the opposite result since LBP could affect lumbar spine curvatures [60-62].

The increased sacral slope in individuals with LSTV could lie within the potential effect of vertebral transition upon the normal biomechanics of lumbar spine. This means that modification of sacral slope in individuals with LSTV could be related to the alteration of trajectories applied upon lumbar spine. As mentioned above, disc height supradjacent to the LSTV tends to be reduced $[26,54]$. Furthermore, attenuated L5 vertebral heights in individuals with L5-S1 fusion have been reported [59]. Therefore, reduction of the spine length is expected, resulting in increased lumbar curvature due to diminishing of Delmas index [63].

4.1. Limitation of the Study. This is a retrospective research and the outcomes should be supported by well-established prospective studies. Additionally, the sample size of the control group was relatively small and a large-scale population with LSTV is needed to shed light on this phenomenon and to reveal its association with lumbar spine alterations.

\section{Conclusions}

The current study shows that the prevalence of LSTV is significantly greater in the stenosis group compared to control. The presence of LSTV may increase the likelihood of developing DLSS; however, no causal relationship is reported. The LSTV is gender-dependent and may exaggerate sacral curvature.

\section{Data Availability}

The data used to support the findings of this study are available from the corresponding author upon request.

\section{Disclosure}

The abstract of this manuscript has been published in the 3rd International Conference on Spine and Spinal Disorders, June 2018.

\section{Conflicts of Interest}

The authors declare that they have no conflicts of interest.

\section{Acknowledgments}

The Dan David Foundation, the Tassia and Dr. Joseph Meychan Chair of History and Philosophy of Medicine, and the Israel Science Foundation supported this research (ISF: 1397/08). The authors thank Margie Serling Cohn for her editorial assistance.

\section{References}

[1] J. M. Spivak, "Degenerative lumbar spinal stenosis," The Journal of Bone \& Joint Surgery, vol. 80, no. 7, pp. 1053-1066, 1998.
[2] E. Arbit and S. Pannullo, "Lumbar stenosis: a clinical review," Clinical Orthopaedics and Related Research, no. 384, pp. 137-143, 2001.

[3] S. Konno, Y. Hayashino, S. Fukuhara et al., "Development of a clinical diagnosis support tool to identify patients with lumbar spinal stenosis," European Spine Journal, vol. 16, no. 11, pp. 19511957, 2007.

[4] J. C. Fanuele, W. A. Abdu, B. Hanscom, and J. N. Weinstein, "Association between obesity and functional status in patients with spine disease," The Spine Journal, vol. 27, no. 3, pp. 306$312,2002$.

[5] L. Gary Hart, R. A. Deyo, and D. C. Cherkin, "Physician office visits for low back pain: frequency, clinical evaluation, and treatment patterns from a u.s. national survey," The Spine Journal, vol. 20, no. 1, pp. 11-19, 1995.

[6] W. H. Kirkaldy-Willis, J. H. Wedge, K. Yong-Hing, and J. Reilly, "Pathology and pathogenesis of lumbar spondylosis and stenosis," The Spine Journal, vol. 3, no. 4, pp. 319-328, 1978.

[7] W. H. Kirkaldy-Willis and G. W. McIvor, "Spinal stenosis," Clin Orthop, vol. 115, pp. 2-144, 1976.

[8] K. Yong-Hing and W. H. Kirkaldy-Willis, "The pathophysiology of degenerative disease of the lumbar spine," Orthopedic Clinics of North America, vol. 14, pp. 491-515, 1983.

[9] J. Abbas, K. Hamoud, Y. M. Masharawi et al., "Ligamentum flavum thickness in normal and stenotic lumbar spines," The Spine Journal, vol. 35, no. 12, pp. 1225-1230, 2010.

[10] A. E. Castellvi, L. A. Goldstein, and D. P. Chan, "Lumbosacral transitional vertebrae and their relationship with lumbar extradural defects," The Spine Journal, vol. 9, no. 5, pp. 493-495, 1984.

[11] N. C. Paik, C. S. Lim, and H. S. Jang, "Numeric and morphological verification of lumbosacral segments in 8280 consecutive patients," The Spine Journal, vol. 38, no. 10, pp. E573-E578, 2013.

[12] G. P. Konin and D. M. Walz, "Lumbosacral transitional vertebrae: Classification, imaging findings, and clinical relevance," American Journal of Neuroradiology, vol. 31, no. 10, pp. 17781786, 2010.

[13] A. Apazidis, P. A. Ricart, C. M. Diefenbach, and J. M. Spivak, "The prevalence of transitional vertebrae in the lumbar spine," The Spine Journal, vol. 11, no. 9, pp. 858-862, 2011.

[14] M. Tang, X.-F. Yang, S.-W. Yang et al., "Lumbosacral transitional vertebra in a population-based study of 5860 individuals: prevalence and relationship to low back pain," European Journal of Radiology, vol. 83, no. 9, pp. 1679-1682, 2014.

[15] L. Nardo, H. Alizai, W. Virayavanich et al., "Lumbosacral transitional vertebrae: association with low back pain," Radiology, vol. 265, no. 2, pp. 497-503, 2012.

[16] D. Uçar, B. Y. Uçar, Y. Coşar et al., "Retrospective cohort study of the prevalence of lumbosacral transitional vertebra in a wide and well-represented population," Arthritis, vol. 2013, Article ID 461425, 5 pages, 2013.

[17] D. Tureli, G. Ekinci, and F. Baltacioglu, "Is any landamark reliable in vertebral enumeration? A study of 3.0-tesla lumbar MRI comparing skeletal, neural and vascular markers," Clinical Imaging, vol. 195, pp. 466-466, 2014.

[18] C. M. O'Driscoll, A. Irwin, and A. Saifuddin, "Variations in morphology of the lumbosacral junction on sagittal MRI: correlation with plain radiography," Skeletal Radiology, vol. 25, no. 3, pp. 225-230, 1996.

[19] B. Y. Ucar, D. E. Ucar, M. Bulut et al., "Lumbosacral transitional vertebrae in low back pain population," The Spine Journal, vol. 2, Article ID 1000125, 2013. 
[20] R. E. Wigh and H. F. Anthony, "Transitional lumbosacral discs: probability of herniation," The Spine Journal, vol. 6, no. 2, pp. 168-171, 1981.

[21] A. D. Elster, "Bertolotti's syndrome revisited: transitional vertebrae of the lumbar spine," The Spine Journal, vol. 14, no. 12, pp. 1373-1377, 1989.

[22] K. Luoma, T. Vehmas, R. Raininko, R. Luukkonen, and H. Riihimäki, "Lumbosacral transitional vertebra: relation to disc degeneration and low back pain," The Spine Journal, vol. 29, no. 2, pp. 200-204, 2004.

[23] K. Otani, S. Konno, and S. Kikuchi, "Lumbosacral transitional vertebrae and nerve-root symptoms," The Journal of Bone \& Joint Surgery (British Volume), vol. 83, no. 8, pp. 1137-1140, 2001.

[24] M. Secer, J. M. Muradov, and A. Dalgic, "Evaluation of congenital lumbosacral malformations and neurological findings in patients with low back pain," Turkish neurosurgery, vol. 19, no. 2, pp. 145-148, 2009.

[25] P. G. Tini, C. Wieser, and W. M. Zinn, "The transitional vertebra of the lumbosacral spine: its radiological classification, incidence, prevalence, and clinical significance," Rheumatology, vol. 16, no. 3, pp. 180-185, 1977.

[26] S. Vergauwen, P. M. Parizel, L. Van Breusegem et al., "Distribution and incidence of degenerative spine changes in patients with a lumbo-sacral transitional vertebra," European Spine Journal, vol. 6, no. 3, pp. 168-172, 1997.

[27] M. Chalian, T. Soldatos, J. A. Carrino et al., "Prediction of transitional lumbosacral anatomy on magnetic resonance imaging of the lumbar spine," World Journal of Radiology, vol. 4, no. 3, pp. 97-101, 2012.

[28] I. C. Benlidayi, N. C. Coskun, and S. Basaran, "Does lumbosacral transitional vertebra have any influence on sacral tilt?" The Spine Journal, vol. 40, no. 22, pp. E1176-E1179, 2015.

[29] J. Abbas, V. Slon, D. Stein, N. Peled et al., "In the quest for degenerative lumbar spinal stenosis etiology: the Schmorl's nodes model," BMC Musculoskeletal Disorders, vol. 18, no. 1, article 164, 2017.

[30] J. N. Katz, M. Dalgas, G. Stucki et al., "Degenerative lumbar spinal stenosis diagnostic value of the history and physical examination," Arthritis \& Rheumatism, vol. 38, no. 9, pp. 12361241, 1995.

[31] J. A. Turner, M. Ersek, L. Herron, and R. Deyo, "Surgery for lumbar spinal stenosis: attempted meta-analysis of the literature," The Spine Journal, vol. 17, no. 1, pp. 1-8, 1992.

[32] N. Schönström, S. Lindahl, J. Willén, and T. Hansson, "Dynamic changes in the dimensions of the lumbar spinal canal: an experimental study in vitro," Journal of Orthopaedic Research, vol. 7, no. 1, pp. 115-121, 1988.

[33] N. F. Bolender, N. S. R. Schonstrom, and D. M. Spengler, "Role of computed tomography and myelography in the diagnosis of central spinal stenosis," The Journal of Bone \& Joint Surgery, vol. 67, no. 2, pp. 240-246, 1985.

[34] N. S. R. Schonstrom, N.-F. Bolender, and D. M. Spengler, "The pathomorphology of spinal stenosis as seen on CT scans of the lumbar spine," The Spine Journal, vol. 10, no. 9, pp. 806-811, 1985.

[35] P. Suri, J. Rainville, L. Kalichman, and J. N. Katz, "Does this older adult with lower extremity pain have the clinical syndrome of lumbar spinal stenosis?" The Journal of the American Medical Association, vol. 304, no. 23, pp. 2628-2636, 2010.

[36] H. Verbiest, "Pathomorphologic aspect of developmental lumbar stenosis," Orthopedic Clinics of North America, vol. 6, no. 1, pp. 177-196, 1975.
[37] H. Verbiest, "Results of surgical treatment of idiopathic developmental stenosis of the lumbar vertebral canal: a review of twenty-seven years' experience," The Journal of Bone \& Joint Surgery (British Volume), vol. 59, pp. 181-188, 1997.

[38] A. B. Ferguson, "The clinical and roentgenographic interpretation of lumbosacral anomalies," Radiology, vol. 22, no. 5, pp. 548-558, 1934.

[39] J. R. Cobb, "Outline for the study of scoliosis," Instructional Course Lectures, vol. 5, pp. 261-275, 1948.

[40] H. S. Chang and H. Nakagawa, "Altered function of lumbar nerve roots in patients with transitional lumbosacral vertebrae," The Spine Journal, vol. 29, no. 15, pp. 1632-1635, 2004.

[41] E. G. Delport, T. R. Cucuzzella, N. Kim, J. K. Marley, C. Pruitt, and A. G. Delport, "Lumbosacral transitional vertebrae: incidence in a consecutive patient series," Pain Physician, vol. 9, no. 1, pp. 53-56, 2006.

[42] M. A. Taskaynatan, Y. Izci, A. Ozgul, B. Hazneci, H. Dursun, and T. A. Kalyon, "Clinical significance of congenital lumbosacral malformations in young male population with prolonged low back pain," Spine, vol. 30, no. 8, pp. E210-213, 2005.

[43] J. L. Bron, B. J. van Royen, and P. I. Wuisman, "The clinical significance of lumbosacral transitional anomalies," Acta Orthopaedica Belgica, vol. 73, no. 6, pp. 687-695, 2007.

[44] G. Cinotti, F. Postacchini, F. Fassari, and S. Urso, "Predisposing factors in degenerative spondylolisthesis. A radiographic and CT study," International Orthopaedics, vol. 21, no. 5, pp. 337-342, 1997.

[45] G. P. Pal, L. Cosio, and R. V. Routal, "Trajectory architecture of the trabecular bone between the body and the neural arch in human vertebrae," The Anatomical Record, vol. 222, no. 4, pp. 418-425, 1988.

[46] N. K. Mahato, "Lumbosacral transitional vertebrae: variations in low back structure, biomechanics, and stress patterns," Journal of Chiropractic Medicine, vol. 11, no. 2, pp. 134-135, 2012.

[47] J. S. Brault, J. Smith, and B. L. Currier, "Partial lumbosacral transitional vertebra resection for contralateral facetogenic pain," The Spine Journal, vol. 26, no. 2, pp. 226-229, 2001.

[48] T. Aihara, K. Takahashi, Y. Ono, and H. Moriya, "Does the morphology of the iliolumbar ligament affect lumbosacral disc degeneration?" The Spine Journal, vol. 27, no. 14, pp. 1499-1503, 2002.

[49] B. Zhang, L. Wang, H. Wang, Q. Guo, X. Lu, and D. Chen, "Lumbosacral transitional vertebra: possible role in the pathogenesis of adolescent lumbar disc herniation," World Neurosurgery, vol. 107, pp. 983-989, 2017.

[50] P. A. Anderson, R. C. Sasso, J. Hipp, D. C. Norvell, A. Raich, and R. Hashimoto, "Kinematics of the cervical adjacent segments after disc arthroplasty compared with anterior discectomy and fusion: a systematic review and meta-analysis," The Spine Journal, vol. 37, no. 22, pp. S85-S95, 2012.

[51] N. K. Mahato, “Trabecular bone structure in lumbosacral transitional vertebrae: distribution and densities across sagittal vertebral body segments," The Spine Journal, vol. 13, no. 8, pp. 932-937, 2013.

[52] W. H. Kirkaldy-Willis and H. F. Farfan, "Instability of the Lumbar Spine," Clinical Orthopaedics and Related Research, vol. 165 , pp. 110-123, 1982.

[53] J. Abbas, V. Slon, D. Stein et al., "In the quest for degenerative lumbar spinal stenosis etiology: the Schmorl's nodes model," BMC Musculoskeletal Disorders, vol. 18, article 164, 2017. 
[54] T. Aihara, K. Takahashi, A. Ogasawara, E. Itadera, Y. Ono, and H. Moriya, "Intervertebral disc degeneration associated with lumbosacral transitional vertebrae: a clinical and anatomical study," The Journal of Bone \& Joint Surgery, vol. 87, no. 5, pp. 687-691, 2005.

[55] D. A. Olanrewaju, "Congenital abnormalities of the lumbosacral spine incidence and significance in adolescent Nigerian," The Nigerian Postgraduate Medical Journal, vol. 1, pp. 1721, 1994.

[56] A. Magora and A. Schwartz, "Relation between the low back pain syndrome and $\mathrm{x}$-ray findings. 2. Transitional vertebra (mainly sacralization)," Scandinavian Journal of Rehabilitation Medicine, vol. 10, no. 3, pp. 135-145, 1978.

[57] B. O. Igbinedion and A. Akhigbe, "Correlations of radiographic findings in patients with low back pain," Nigerian Medical Journal, vol. 52, pp. 28-34, 2011.

[58] J. A. Miller, C. Schmatz, and A. B. Schultz, "Lumbar disc degeneration: correlation with age, sex, and spine level in 600 autopsy specimens," The Spine Journal, vol. 13, no. 2, pp. 173$178,1988$.

[59] N. K. Mahato, "Disc spaces, vertebral dimensions, and angle values at the lumbar region: a radioanatomical perspective in spines with L5-S1 transitions - Clinical article," Journal of Neurosurgery: Spine, vol. 15, no. 4, pp. 371-379, 2011.

[60] R. McRae, Clinical Orthopaedic Examination, Churchill Livingstone, New York, NY, USA, 4th edition, 1997.

[61] H. J. Christie, S. Kumar, and S. A. Warren, "Postural aberrations in low back pain," Archives of Physical Medicine and Rehabilitation, vol. 76, no. 3, pp. 218-224, 1995.

[62] I. Coskun Benlidayi and S. Basaran, "Comparative study of lumbosacral alignment in elderly versus young adults: data on patients with low back pain," Aging Clinical and Experimental Research, vol. 27, no. 3, pp. 297-302, 2015.

[63] I. A. Kapandji, The Physiology of the Joints: The Trunk and the Vertebral Column, vol. 3, Churchil Livenston, 2nd edition, 1974. 


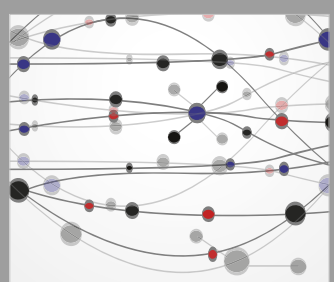

The Scientific World Journal
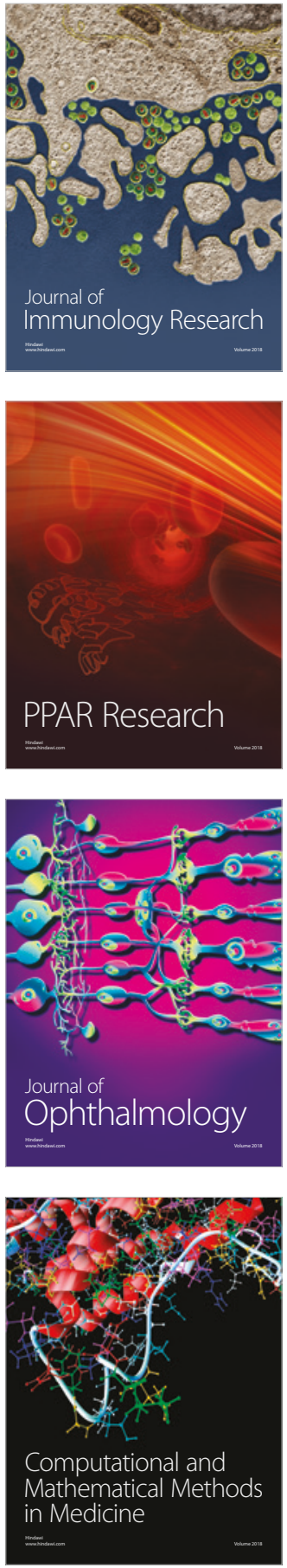

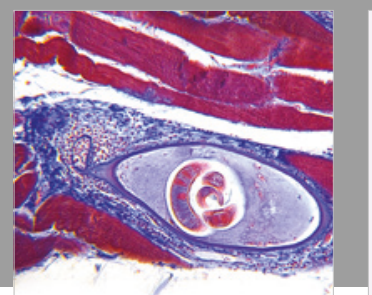

Gastroenterology Research and Practice

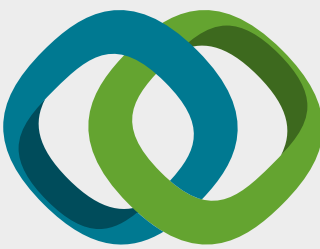

\section{Hindawi}

Submit your manuscripts at

www.hindawi.com
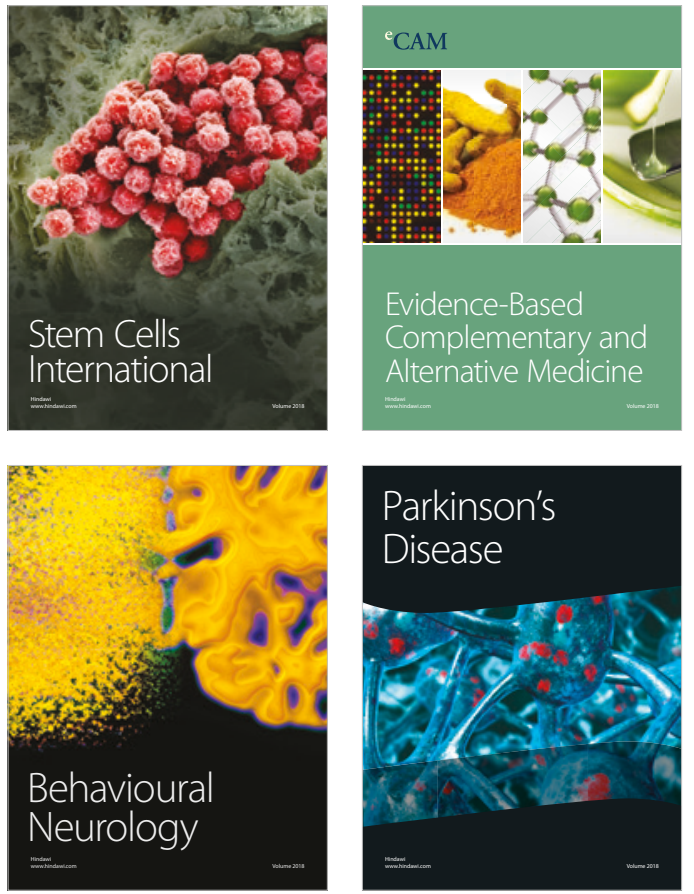

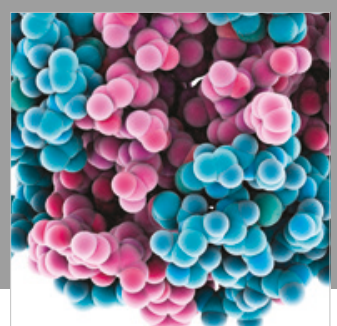

ournal of

Diabetes Research

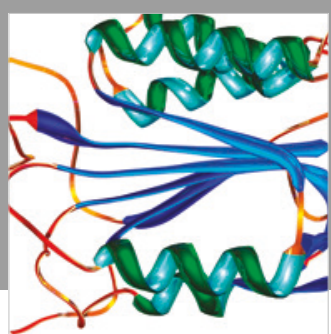

Disease Markers
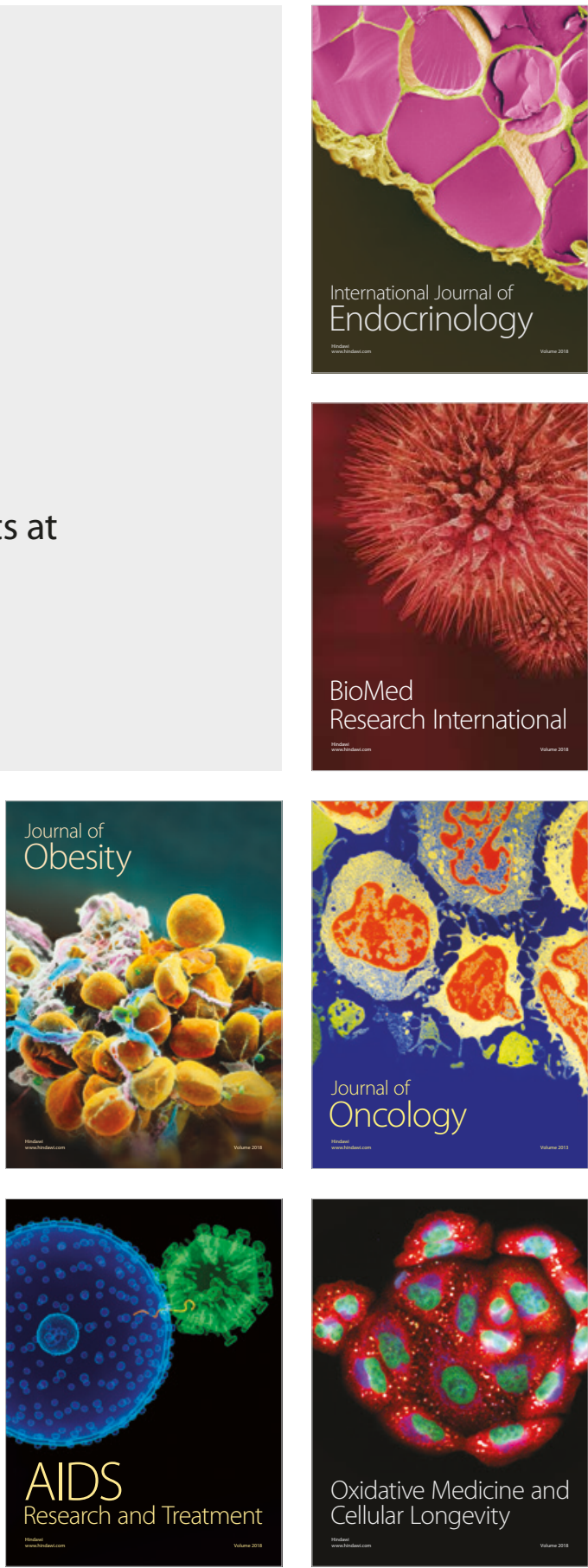